\title{
Neurophysiological correlates of cognitive control and approach motivation abnormalities in adolescent bipolar disorders
}

\author{
Erin L. Maresh ${ }^{1,2} \cdot$ Joshua J. Stim ${ }^{1,3} \cdot$ Abraham C. Van Voorhis $^{1} \cdot$ Seung Suk Kang ${ }^{1,4} \cdot$ Monica Luciana $^{3}$. \\ Scott R. Sponheim ${ }^{1,5} \cdot$ Snežana Urošević ${ }^{1,5}$ \\ Published online: 16 May 2019 \\ (C) This is a U.S. government work and its text is not subject to copyright protection in the United States; however, its text may be subject to foreign copyright \\ protection 2019
}

\begin{abstract}
Hypersensitivity to reward-relevant stimuli is theorized to be a core etiological factor in bipolar disorders (BDs). However, little is known about the role of cognitive control dysregulation within reward contexts in BDs, particularly during adolescence. Using electroencephalography (EEG), we explored alterations in cognitive control processes and approach motivation in 99 adolescents with $(\mathrm{n}=53)$ and without $(\mathrm{n}=46) \mathrm{BD}$ during reward striving (target anticipation) and reward attainment (feedback) phases of a monetary incentive delay (MID) task. Time-frequency analysis yielded frontal theta and frontal alpha asymmetry as indices of cognitive control and approach motivation, respectively. Multilevel mixed models examined group differences, as well as age, sex, and other effects, on frontal theta and frontal alpha asymmetry during both phases of the task and on performance accuracy and reaction times. Healthy adolescent girls exhibited lower frontal theta than both adolescent girls with BD and adolescent boys with and without $\mathrm{BD}$ during reward anticipation and feedback. Across groups, adolescent boys displayed greater relative left frontal alpha activity than adolescent girls during reward anticipation and feedback. Behaviorally, adolescents with BD exhibited faster responses on both positively and negatively motivated trials versus neutral trials, whereas healthy adolescents had faster responses only on positively motivated trials; adolescents with $\mathrm{BD}$ were less accurate in responding to neutral trials compared to healthy controls. These findings shed light on normative and BD-specific involvement of approach motivation and cognitive control during different stages of reward processing in adolescence and, further, provide evidence of adolescent sex differences in these processes.
\end{abstract}

Keywords Bipolar disorder $\cdot$ Adolescence $\cdot$ Reward $\cdot$ Cognitive control $\cdot$ EEG

Electronic supplementary material The online version of this article (https://doi.org/10.3758/s13415-019-00719-x) contains supplementary material, which is available to authorized users.

Snežana Urošević

snezana.urosevic@gmail.com

1 Minneapolis VA Health Care System, Psychology Services \#116B, One Veterans Drive, Minneapolis, MN 55417, USA

2 Department of Psychology, University of Arizona, Tucson, AZ, USA

3 Department of Psychology, University of Minnesota-Twin Cities, Minneapolis, MN, USA

4 Department of Psychiatry, University of Missouri-Kansas City, Kansas City, MI, USA

5 Department of Psychiatry, University of Minnesota-Twin Cities, Minneapolis, MN, USA

\section{Introduction}

Bipolar disorders (BDs) are chronic and often debilitating mental illnesses. Affecting almost 5\% of the adult population worldwide (Merikangas et al., 2011), BDs are the sixth leading cause of disability among mental disorders (Whiteford et al., 2013) with high rates of completed suicide (Baldessarini, Pompili, \& Tondo, 2006). While the average age of onset for BD is between 18 and 25 years (Tozzi et al., 2011), adolescence has been identified as a period of high risk for developing BD (Beesdo et al., 2009; Birmaher et al., 2014; Tozzi et al., 2011). Further, early onset of BD is associated with a more severe disease course (Perlis et al., 2004, 2009; Pompili et al., 2013; Schürhoff et al., 2000). Research implicates dysregulated cognitive control and reward systems as core etiological components of BD in adults (Depue \& Iacono, 1989; Johnson, Fulford, \& Carver, 2012; Swann, 2010; Urošević, Abramson, Harmon-Jones, \& Alloy, 2008), 
but little research has examined abnormalities in these neural networks in BD during adolescence, a developmental period already characterized by significant normative changes in the structure and functioning of cognitive control and reward neural networks (Porter et al., 2015; Somerville, Hare, \& Casey, 2011; Urošević, Collins, Muetzel, Lim, \& Luciana, 2012). Examining cognitive control processes within reward contexts in BD could shed light on how BD-specific dysfunctions of these two systems interact, in particular during adolescence, where BD may disrupt normative developmental processes.

According to the behavioral approach system (BAS) dysregulation theory of $\mathrm{BD}$, individuals with $\mathrm{BD}$ experience extreme fluctuations in activation and deactivation of the BAS, a psychobiological system involved in goal-seeking and reward responsiveness (Depue \& Iacono, 1989; Johnson, Fulford, \& Carver, 2012; Urošević, Abramson, Harmon-Jones, \& Alloy, 2008). This BAS hypersensitivity leads to periods of extreme approach motivation during goal/reward striving and periods of decreased or absent approach motivation in response to reward loss or failures to obtain rewards/goals (e.g., Fulford, Johnson, Llabre, \& Carver, 2010; Urošević et al., 2010). Consistent with this theoretical model, adults with BD and adults at risk for BD report heightened BAS sensitivity (Alloy et al., 2008; Meyer, Johnson, \& Carver, 1999; Meyer, Johnson, \& Winters, 2001) and show hyperactivity in BASrelated neural regions when anticipating a reward (Bermpohl et al., 2010; Dutra, Cunningham, Kober, \& Gruber, 2015; Harmon-Jones et al., 2008; Nusslock et al., 2012).

Alterations in frontal alpha asymmetry observed in adults with BD and at risk for BD further support the BAS dysregulation model of BD. Despite some studies linking frontal alpha asymmetry to other psychological processes (Ambrosini \& Vallesi, 2016; Smith, Zambrano-Vazquez, \& Allen, 2016), there is a broad and strong empirical support for frontal alpha asymmetry indexing motivational tendencies, with greater relative left frontal activity (indexed by less left frontal alpha) implicated in heightened approach motivation (e.g., Coan \& Allen, 2004; Harmon-Jones, Gable, \& Peterson, 2010; Quaedflieg, Meyer, Smulders, \& Smeets, 2015). Consistent with this, greater relative left frontal activity has been observed in young adults high in mania proneness (Harmon-Jones et al., 2002), as well as in euthymic adults with BD during reward anticipation (Harmon-Jones et al., 2008). However, it is unknown whether differences in frontal alpha asymmetry are observable in BDs before adulthood, and, further, when in the reward process such differences occur. BAS dysregulation in BD may be more disruptive during anticipation of reward rather than during actual goal attainment (Fulford et al., 2010; Nusslock, Abramson, HarmonJones, Alloy, \& Hogan, 2007; Urošević et al., 2010), but to date no studies have examined neural abnormalities in BD across different stages of reward processing within the same sample and using measures with high temporal resolution.
In addition to BAS dysregulation, other core dysfunctions in $\mathrm{BD}$ are theorized to involve impulsivity (e.g., Hidiroğlu et al., 2013), which reflects impaired cognitive control - difficulty adapting one's behavior to best fit the current environmental context (e.g., Swann, 2010). Within reward contexts, adults with BD select high, sometimes unattainable, goals, expend excess energy to achieve goals, and show heightened reactivity to both goal attainment and obstacles (for review, see Johnson et al., 2012). In other words, while adults with BD may exhibit increased goal striving, they may also lack control mechanisms to alert them to adaptive behavior changes when goal striving is not going well. However, this hypothesis has not been tested directly.

Frontal theta, a range of frequencies between 5 and $7 \mathrm{~Hz}$ that is prominent over frontal midline regions of the cortex, is associated with multiple processes, including attention, working memory, cognitive load, and effort (Burgess \& Gruzelier, 1997; Lazarev, 1998; Missonnier et al., 2006; Wascher et al., 2014). Converging evidence for its role in these processes implicates frontal theta as a mechanism for cognitive control (for meta-analysis, see Cavanagh \& Shackman, 2015). Potentially reflecting difficulties with cognitive control, the few studies that have examined alterations in frontal theta power in adult BD have found that, compared to healthy adults, euthymic adults with BD displayed lower frontal theta during rest (Rommel et al., 2016) and during an auditory oddball task (Atagun, Guntekin, Ozerdem, Tulay, \& Basar, 2013); however, a recent study showed no differences in frontal theta between adults with BD and healthy adults during a reward task (Michelini et al., 2018). To our knowledge, no studies of BD have explored frontal theta abnormalities during adolescence.

Cross-sectional research suggests the neural deficits seen in BD may differ between adolescence and adulthood (Wegbreit et al., 2014), highlighting a long-standing (although waning) debate regarding whether adult and pediatric BDs represent the same or different forms of psychopathology (Goldstein et al., 2017); thus, greater understanding of core BD deficits during adolescence is needed. Major structural and functional changes in cognitive control and BAS neural networks occur during normative adolescent development (Casey, Jones, \& Hare, 2008; Luna, Padmanabhan, \& O'Hearn, 2010; Porter et al., 2015; Urošević et al., 2012). Improvements in cognitive control functioning are generally observed during maturation from adolescence into adulthood (Olson, Hooper, Collins, \& Luciana, 2007; Steinberg et al., 2008; Velanova, Wheeler, \& Luna, 2008), whereas changes in reward-sensitive neural regions during development appear to follow a curvilinear trajectory, increasing during childhood, peaking in adolescence, and leveling out during early adulthood (Ernst et al., 2005; Galvan et al., 2006; Urošević et al., 2012). Correspondingly, adolescents exhibit heightened sensitivity to rewards compared to children or adults (Steinberg et al., 2008; Urošević et al., 2012). 
The present study used electroencephalography (EEG) to examine neural correlates of cognitive control and approach motivation during reward processing in adolescents (ages 1319 years) with and without BD. The few studies that have examined these questions in adolescent BD have relied on neuroimaging techniques with low temporal sensitivity (Pavuluri et al., 2009; Urošević et al., 2016), which limits accurate examination of abnormalities in BD across different reward-processing stages. The precise temporal resolution of EEG allowed us to examine neural oscillatory behavior during two different stages of reward processing - reward anticipation and reward feedback - within the monetary incentive delay (MID) task (Knutson, Westdorp, Kaiser, \& Hommer, 2000). Past research using MRI-based neuroimaging techniques has been mixed in its ability to separate neural activity unique to each stage of the MID task (e.g., Knutson, Fong, Adams, Varner, \& Hommer, 2001; Liu, Hairston, Schrier, \& Fan, 2011). Thus, exploring separate stages of the MID using EEG indices will allow for a more refined examination of neural abnormalities in adolescent $\mathrm{BD}$ and also contribute to our understanding of potential differences between these stages in normative adolescence.

The present study addresses several remaining key questions about BAS and cognitive control dysregulation in BD. First, while alterations in frontal alpha asymmetry have been observed during rest and during anticipation of experimental rewards, these findings need to be replicated and extended to see whether approach dysregulation in BD also occurs during reward attainment. Second, although cognitive difficulties are well documented in $\mathrm{BD}$, it is unclear whether poor cognitive control may contribute to dysregulated processing of rewards, and if so, if this cognitive control dysfunction is related to reward striving, attainment, or both. Finally, little is known about how BD-specific deficits disrupt development of cognitive control and approach motivation during adolescence. To address these knowledge gaps, frontal theta and frontal alpha asymmetry were examined during both reward anticipation and feedback of the MID task, allowing us to examine the effects of diagnostic group, trial type, and chronological age on these processes during both stages of reward processing. We first hypothesized that adolescents with BD would exhibit lower frontal theta and higher frontal alpha asymmetry (suggesting higher relative left frontal activity) compared to healthy adolescents, given evidence of impaired cognitive control and elevated approach motivation in adult BD. Second, we hypothesized that healthy adolescents would display developmentally normative increases in cognitive control and decreases in approach motivation with older age, whereas adolescents with BD would show disruptions in these normative age associations. Third, we hypothesized that group differences in cognitive control and approach motivation would be most prominent during trials in which participants had the opportunity to win money (vs. prevent losing money or break even), given prior evidence suggesting positive motivational cues may be more salient in BD than negative motivational cues (Harmon-Jones et al., 2008). Finally, we additionally explored the role of sex in these processes due to evidence for sex-specific development in normative adolescence (e.g., Urošević et al., 2012, 2014).

\section{Methods}

\section{Participants and recruitment}

An initial sample of 107 adolescents (ages 13-19 years) was recruited from university-affiliated clinics, a database of community research volunteers, and community flyers. Participants in the healthy control group (HC) did not meet criteria for any DSM-IV-TR Axis I disorders, except for one participant who had a history of enuresis. Participants in the BD group met DSM-IV-TR criteria for Bipolar I Disorder, Bipolar II Disorder, or Bipolar Disorder Not Otherwise Specified (NOS). Other general inclusion criteria were: no neurological disorders or severe head injury; no current major/chronic physical conditions; IQ > 70; no learning disabilities/developmental problems; normal or corrected-tonormal vision and hearing; native English speaker or bilingual since early age; right-handedness; and no imaging contraindications (as this was part of a larger study that included neuroimaging). Six participants (4 BD, 2 HC) were excluded from the present analyses due to EEG data-recording technical difficulties, and two participants with BD were excluded from analyses for having negative total winnings at the end of the task. The final sample consisted of 99 adolescents (BD $n=43$, $\mathrm{HC} \mathrm{n}=56$ ), which is a larger or comparable sample to those of other EEG studies examining adult BD (e.g., Harmon-Jones et al., 2008). Demographic information is provided in Table 1.

In the BD group, all participants with Bipolar Disorder NOS also met DSM-5 criteria for Other Specified Bipolar Disorder due to presence of short-duration hypomanic episodes (< 4 days) and major depressive episodes. The inclusion of BD NOS is consistent with evidence suggesting that BD NOS is an impairing disorder on a continuum with Bipolar I Disorder (Hafeman et al., 2013; Youngstrom, 2009) and shows high rates of eventual conversion to Bipolar I or II Disorder (Alloy et al., 2012). There were also no differences in EEG activity in frontal theta or frontal alpha asymmetry indices between adolescents with BD I and adolescents with BD II or BD NOS $(p>.05)$. Diagnoses were determined through an in-person semi-structured diagnostic interview using the Kiddie-SADS-Present and Lifetime Version 2009 (K-SADS-PL, 2009; Axelson, Birmaher, Zelazny, Kaufman, $\&$ Gill, 2009). For minors (< 18 years old), different interviewers conducted an interview with a parent versus the participant, whereas adult participants provided all information 
Table 1 Demographic and clinical information

\begin{tabular}{|c|c|c|c|c|}
\hline & $\mathrm{BD}(\mathrm{n}=43)$ & $\mathrm{HC}(\mathrm{n}=56)$ & $t / \chi^{2}$ value & $p$-value \\
\hline Age, M (SD) & $16.2(1.8)$ & $15.8(1.8)$ & 1.13 & 0.26 \\
\hline Female, n (\%) & $24(56 \%)$ & $25(45 \%)$ & .81 & 0.37 \\
\hline White, n (\%) & $29(67 \%)$ & $45(80 \%)$ & 1.52 & 0.22 \\
\hline IQ, M (SD) & $106.60(12.38)$ & $114.88(10.67)$ & 3.57 & $<.001$ \\
\hline ISS-Activation, M (SD) & $150.70(106.76)$ & $73.57(68.32)$ & 4.37 & $<.0001$ \\
\hline ISS-Depression, M (SD) & $37.91(40.45)$ & $7.5(17.81)$ & 5.03 & $<.0001$ \\
\hline Medication, n (\%) & $38(88 \%)$ & 0 & & \\
\hline BD diagnosis, $\mathrm{n}(\%)$ & & N/A & & \\
\hline BD I & $18(42 \%)$ & & & \\
\hline BD II & $13(30 \%)$ & & & \\
\hline BD NOS & $12(28 \%)$ & & & \\
\hline Clinical state, n (\%) & & N/A & & \\
\hline Euthymic & $14(33 \%)$ & & & \\
\hline Hypomanic & $11(26 \%)$ & & & \\
\hline Depressed & $7(16 \%)$ & & & \\
\hline Mixed & $11(26 \%)$ & & & \\
\hline Other diagnoses, $\mathrm{n}(\%)$ & & N/A & & \\
\hline Anxiety disorder & $30(70 \%)$ & & & \\
\hline ADHD & $17(40 \%)$ & & & \\
\hline SUD & $11(26 \%)$ & & & \\
\hline Eating disorder & $11(26 \%)$ & & & \\
\hline $\mathrm{ODD} / \mathrm{CD}$ & $6(14 \%)$ & & & \\
\hline
\end{tabular}

ISS Internal State Scale, $A D H D$ attention-deficit hyperactivity disorder, $S U D$ substance use disorder, $O D D / C D$ oppositional defiant disorder/conduct disorder

themselves. A two-tiered consensus procedure was employed for deriving DSM-IV-TR diagnoses and summary symptom ratings based on all available information (for details see Urošević, Luciana, Jensen, Youngstrom, \& Thomas, 2016). Consistent with Axelson et al. (2009), only bipolar symptoms that started, or chronic symptoms that worsened, with the onset of mood episodes counted towards bipolar symptomatology. Inter-rater reliability for K-SADS-PL-2009 symptom assessments was excellent (weighted kappa=.87).

To assess current clinical state, BD-group participants were administered an interview assessment of bipolar symptoms in the week prior to testing, i.e., the K-SADS Depression Rating Scale (KDRS) and K-SADS Mania Rating Scale (KMRS; Ladouceur et al., 2011). Based on established cut-offs (Ladouceur et al., 2011), 14 BD participants were euthymic (KDRS $<10$ and KMRS $<12$ ), 11 participants exhibited depressive and hypomanic symptoms (KDRS $\geq 10$ and KMRS $\geq$ 12), 11 participants exhibited hypomanic symptoms only (KDRS $<10$ and KMRS $>12$ ), and seven participants exhibited depressive symptoms only (KDRS $\geq 10$ and KMRS $<$ 12). Additionally, depression and mania symptom severities for the $24 \mathrm{~h}$ prior to testing were assessed using the Internal State Scales (ISS) Depression and Activation subscales, respectively (Bauer et al., 1991). Prior studies have found similar neural activation to reward in adults with BD whether experiencing euthymia (e.g., Nusslock et al., 2012) or acute mania (e.g., Bermpohl et al., 2010), as well as a significant presence of bipolar symptoms outside of bipolar episodes (e.g., Judd et al., 2003). Further, periods of bipolar symptoms that do not reach episode criteria are common in pediatric $\mathrm{BD}$ (Axelson et al., 2006). Thus, to assess neural differences in adolescents with BD irrespective of current clinical state, the ISS Depression and Activation subscales were included as covariates in all analyses; for analyses without ISS subscale covariates, see the Supplemental Materials.

In the $\mathrm{BD}$ group, the most common lifetime co-morbidities were anxiety disorders $(69.8 \%)$, attention deficit/hyperactivity disorder (ADHD; 39.5\%), eating disorders $(25.6 \%)$, and substance-use disorders (SUD; 25.6\%). Six BD participants met current SUD criteria for cannabis and/or alcohol; of these, three were in DSM-IV-defined early full remission and three were symptomatic but denied use in the last $24 \mathrm{~h}$ (or longer) prior to testing. All participants, regardless of substance use history, were asked to abstain from substance use for $24 \mathrm{~h}$ prior to testing. Consistent with prior studies of pediatric BD (e.g., Singh et al., 2013), BD participants remained on their psychotropic medications due to ethical considerations. BD group participants were taking on average $2.63(S D=1.58)$ 
psychotropic medications with the most frequent medication categories being antipsychotics (72\% of participants), ADHD medications (35\%), antidepressants (33\%), and mood stabilizers $(23 \%)$.

\section{Procedures}

After complete description of the study to the participant and a parent or legal guardian, informed assents/consents were obtained prior to data collection. The University of Minnesota's Institutional Review Board approved the study protocol. Participants completed two visits: (1) a semi-structured diagnostic interview, self-report questionnaires, and intelligence testing; and (2) a neurobehavioral task battery, neuroimaging, and psychophysiological assessments. The present analyses include age, sex, current symptom self-report assessments, intelligence as assessed by the Vocabulary and Matrix Reasoning subtests (Wechsler Abbreviated Scale of Intelligence-Second Edition (WASI-II); Wechsler, 2011), and the MID task's behavioral and electroencephalography (EEG) measures. Participants received monetary compensation for their participation, which included a portion of their winnings from the MID task.

\section{Measures}

Internal State Scale (ISS; Bauer et al., 1991) The ISS is a selfreport measure of current bipolar symptoms (across the previous $24 \mathrm{~h}$ ) with four subscales (Activation, Well-being, Perceived Conflict, and Depression). ISS Activation and Depression scores correlate highly with interview-based ratings of mania and depression, respectively (Bauer et al., 1991), and were included as covariates in statistical analyses.

Monetary incentive delay task The monetary incentive delay (MID) task is designed to assess neural responses to the anticipation and receipt of rewarding or punishing monetary stimuli (Knutson et al., 2001). Following introductory practice trials, participants completed three 60-trial blocks of the MID task, for a total of 180 trials, while EEG was recorded. A typical trial sequence is depicted in Fig. 1. At the beginning of each trial, a cue shape indicating either the potential to win money ("gain" cues; 72 trials), the potential to lose money ("loss" cues; 72 trials), or that no money would be won or lost ("neutral" cue; 36 trials), was presented for $250 \mathrm{~ms}$. Horizontal lines across cue shapes represented the magnitude of potential monetary win or loss (from US\$0.25 to US\$5.00). After presentation of the cue, a fixation cross was displayed for $1,500 \mathrm{~ms}$, followed by presentation of a white target square for 180-280 ms. Participants were instructed, upon seeing the target square, to press a button on a provided button box as quickly as possible to gain or avoid losing money. The duration of target presentation was adjusted for each participant to achieve approximately $70 \%$ accuracy, i.e., successfully pressing the button during the target presentation time window. The adjustment algorithm rank-ordered the prior block's reaction times (RTs; for the first block, RTs from the practice trials were used) from the fastest to the slowest and then chose the RT at the 70th percentile as the target duration for the current block. A feedback screen, presented for 1,650 ms, displayed whether they had won or lost money during that trial, and a final screen displayed for $500 \mathrm{~ms}$ displayed their total cumulative earnings. At the end of the task, participants received a portion of their total winnings.

EEG recording and preprocessing EEG data were collected using a 128-channel Geodesic Sensor Net (GSN128; Electrical Geodesics Inc., Eugene, OR; http://www.egi.com) referenced to vertex $(\mathrm{Cz})$, amplified, and digitized $(250 \mathrm{~Hz})$. All electrode impedances were under 100 kilo-ohms. Highpass $0.50-\mathrm{Hz}$ and low-pass $80-\mathrm{Hz}$ filters were applied. Artifact rejection was conducted using an independent components analysis (ICA)-based pipeline using custom-developed scripts in Matlab (Kang et al., 2018). To ensure efficient IC decomposition, highly noisy electrodes (temporal correlation $<0.45$ with neighboring electrodes for at least one-third of the time series) and time segments (maximum amplitude $>27 \mu$ Vover a majority of electrodes) were removed. Participants were excluded from further analyses if more than $20 \%$ of their data were eliminated by the end of the preprocessing pipeline.

Artifact-free data were re-referenced to an average montage and epoched into 1,750-ms segments for both the anticipation and the feedback phases using EEGLAB (Delorme \& Makeig, 2004). For each trial, the anticipation phase, assessing reward striving processes, was defined as a 1,750-ms epoch from the start of cue presentation to the end of target anticipation (fixation cross); the feedback phase, assessing reward attainment processes, was defined as a 1,750-ms epoch from when the participant responded to the target, spanning feedback delay (fixation cross) and 1,250-ms or more of individual trial feedback (i.e., amount of feedback included depended on the timing of the response; see Fig. 1). Epochs from each phase were baseline-corrected using the 100-ms time interval preceding epoch onset. Because this epoching approach combines a delay period with actual trial feedback for the feedback phase, the Supplemental Materials provide analyses that further subdivide EEG data during the feedback phase into feedback delay and feedback presentation phases.

For power analysis, a fast Fourier transform using a Hamming window was applied to EEG data, and power density $\left(\mathrm{uV}^{2} / \mathrm{Hz}\right)$ was extracted from the theta band $(5-7 \mathrm{~Hz})$ and the alpha band $(8-13 \mathrm{~Hz})$ during the anticipation and feedback phases of the MID task. Frontal theta was calculated as average theta power across four frontal midline sites, including $\mathrm{Fz}$ and $\mathrm{FCz}$ (corresponding to channels 5, 6, 11, and 12 on the 128-channel Geodesic Sensor Net); frontal alpha was 


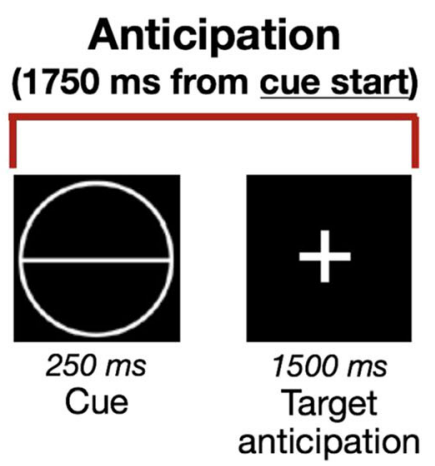

Anticipation (1750 ms from cue start)

Fig. 1 Depiction of a single trial in the monetary incentive delay (MID) task, divided into two EEG epochs representing reward anticipation and feedback, respectively. In this example, the cue type (i.e., circle with one line) indicates a small gain trial, and the feedback screen indicates that the participant responded fast enough during target presentation (white square) to receive reward. Because each feedback epoch started following

calculated as average alpha power across seven electrodes in the right hemisphere centered on F4 (channels 3, 4, 112, 118 119,123 , and 124) and across seven electrodes in the left hemisphere centered on F3 (channels 20, 21, 24, 25, 28, 29, and 30). Frontal theta and frontal alpha values were then natural log-transformed to reduce positive skew. The majority of untransformed power density values in this study fell below 1 $\mathrm{uV}^{2} / \mathrm{Hz}$, which may be due to the decreases in power seen in higher- compared to lower-density arrays (Greischar et al., 2004). As a result, applying a natural log transform resulted in largely negative mean power density values. In interpreting these log-transformed data, it should be noted that less negative values indicate higher power density. Alpha asymmetry was computed as $\ln$ (right alpha) minus ln (left alpha). Because alpha represents an inverse measure of cerebral activity (Coan \& Allen, 2004), reductions in power were interpreted as greater cerebral activity, with more negative asymmetry scores indicating relatively greater right- than left-hemisphere activity and more positive asymmetry scores indicating relatively greater left- than right-hemisphere activity. Topographical maps depicting the distributions of theta and alpha power density for each group (HC and BD) and reward-processing stage (anticipation and feedback) are shown in Fig. 2.

\section{Statistical analyses}

Data were collapsed across magnitudes to yield one value for each trial type (neutral, loss, gain) for each participant. To account for repeated measures in the data, a multilevel mixed effects regression modeling approach was used. This analytic method has several well-documented advantages over more traditional repeated-measures ANOVA approaches, including improved flexibility in modeling continuous-categorical variable interactions, superior handling of non-independent observations, and more robust, unbiased handling of missing data
Feedback (1750 ms from target response)

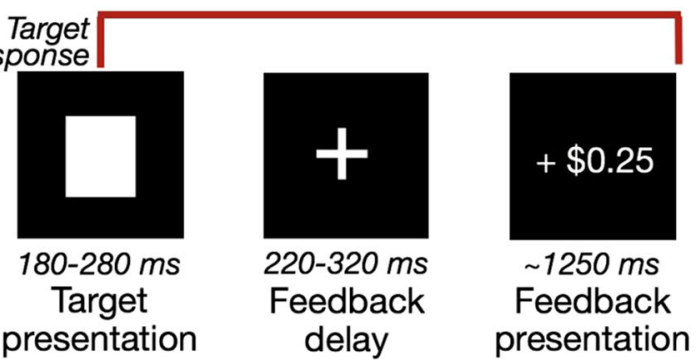

a participant's response to the target, which occurred shortly after target presentation, the amount of time included from feedback presentation varied for each trial to equal a total feedback epoch length of $1,750 \mathrm{~ms}$; the minimum duration of feedback presentation included in the feedback epoch EEG analyses was 1,250 ms

(Baayen, Davidson, \& Bates, 2008; Nich \& Carroll, 1997). Each model was fitted using the "lme4" package in R (Bates, Mächler, Bolker, \& Walker, 2015; R Core Team, 2013) and $p$ values were determined using the package "lmerTest" (Kuznetsova, Brockhoff, \& Christensen, 2014).

Analyses predicting behavioral performance variables used all behavioral data (i.e., including trials that were removed during EEG preprocessing due to artifact). Separate models were conducted for RTs and accuracy. Only correct trials were included in analyses of RTs, as RTs for incorrect trials were recorded as 0 . For analyses predicting EEG indices, four separate models were conducted for the anticipation and feedback phases' frontal theta and frontal alpha asymmetry power density indices. Only correct trials were included in analyses of the feedback phase, as participants are likely to have very different psychological experiences in response to feedback on correct versus incorrect trials. Due to algorithm adjustments of target presentation to ensure $70 \%$ success on the MID task, there were insufficient numbers of incorrect feedback trials to analyze separately. For 13 participants, EEG data for neutral trials were excluded due to fewer than 20 artifactfree trials, but they contributed EEG data for gain and loss trials.

For all models predicting EEG indices or behavioral performance, fixed effects included group (two-level factor: HC and BD), sex (two-level factor: girls and boys), trial type (three-level factor: neutral, loss, and gain), age (continuous; mean-centered), and all two-way, three-way, and four-way interaction terms; random effects included a random intercept for participant. We elected to enter all main effect and interaction terms simultaneously instead of sequentially to reduce type I error from testing multiple models. For models examining associations between behavioral performance and EEG indices, frontal theta or frontal alpha asymmetry were additionally included as predictors, as well as their interactions with other variables. In addition to mean-centering all 

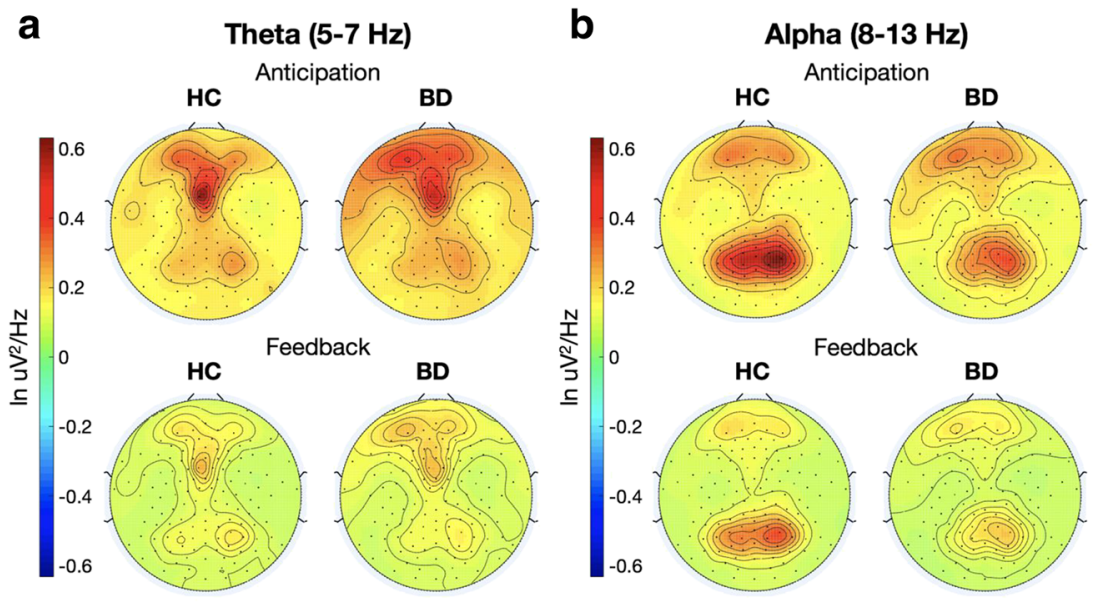

Fig. 2 Topographical maps displaying power density for (A) theta and (B) alpha for both groups (HC and BD) and during both reward processing stages (anticipation and feedback) across all electrodes. $H C$ healthy control, $B D$ bipolar disorder

continuous variables, effects coding was used for contrasts in all categorical variables, allowing for main effects to be interpretable. Finally, for all models, the ISS Activation and Depression subscale scores and IQ scores (based on the WASI-II two-subtest estimates) were modeled as covariates. Models excluding ISS or IQ covariates, as well as models excluding BD participants with co-morbid ADHD, are presented in the Supplemental Materials; overall, the pattern of results in models without covariates was largely similar to those presented here. All $t$-test results include standardized beta coefficients $(\beta)$.

\section{Results}

\section{Behavioral data}

Accuracy Although the MID task adjusted length of target presentation prior to each subsequent run to yield accuracy rates of approximately $70 \%$ across trials, there was a significant main effect of trial type on accuracy $(F(2,182)=95.94$, $p<.0001)$, which was subsumed by a group-by-trial type interaction $(F(2,182)=9.76, p<.0001)$. As illustrated in Fig. 3A, the $\mathrm{HC}$ group performed more accurately during neutral trials than the BD group $(\beta=.26, S E=.10, t(161)=2.60, p=.01)$, while groups did not differ on their accuracy during gain or loss trials. Thus, in comparison with healthy adolescents, adolescents with BD showed worse performance only on trials without motivational value, but comparable accuracy on trials with positive or negative motivational values.

Reaction times When predicting RTs on correct trials, a main effect of trial type emerged $(F(2,182)=7.28, p<.001)$ that was subsumed by a significant group by trial type interaction $(F(2,182)=3.80, p=.02)$. As illustrated in Fig. $3 \mathrm{~B}$, the $\mathrm{BD}$ group responded more quickly to both gain trials $(\beta=.11$,
$S E=.04, t(182)=2.90, p<.01)$ and loss trials $(\beta=.12, S E=.04$, $t(182)=3.26, p<.01)$ compared to neutral trials; their RTs did not differ between gain and loss trials. The HC group responded more quickly to gain trials than to loss trials $(\beta=.09, S E=.03, t(182)=2.70, p<.01)$ and neutral trials $(\beta=.08, S E=.03, t(182)=2.44, p=.02)$, but their RTs did not differ between loss and neutral trials. In other words, adolescents with BD exhibited faster responses to trials with both positive and negative motivational value compared to neutral trials, while healthy adolescents exhibited faster responses to trials with positive motivational value than trials with negative or neutral motivational value.

\section{EEG data}

\section{Frontal theta}

Anticipation phase: During target anticipation, there were significant main effects of group (BD>HC, $\beta=.30, S E=.11$, $t(88)=2.59, p=.01$ ), sex (boys $>\operatorname{girls}, \beta=.26, S E=.10$, $t(88)=2.63, p=.01$ ), and trial type (gain $>$ neutral, $\beta=.04$, $S E=.01, t(182)=5.26, p<.0001 ;$ loss $>$ neutral, $\beta=.04, S E=.01$, $t(182)=5.64, p<.0001)$ on frontal theta, which were qualified by a two-way group-by-sex interaction $(F(1,88)=5.21, p=.02)$ and a three-way group-by-trial type-by-age interaction $(F(2,182)=3.05, p=.05)$.

As seen in Fig. 4A, the two-way group-by-sex interaction indicated that in the HC group frontal theta was lower in adolescent girls than in adolescent boys $(\beta=.48, S E=.13$, $t(88)=3.77, p<.001$ ) during the target anticipation phase, but no such sex effect was found in the BD group. Moreover, the adolescent girls in the $\mathrm{HC}$ group showed lower frontal theta than either sex in the BD group (adolescent girls, $\beta=.52$, $S E=.15, t(88)=3.47, p<.001$, and adolescent boys, $\beta=.35$, $S E=.15, t(88)=2.28, p=0.02)$. There was no group difference in frontal theta between adolescent boys with and without BD. 

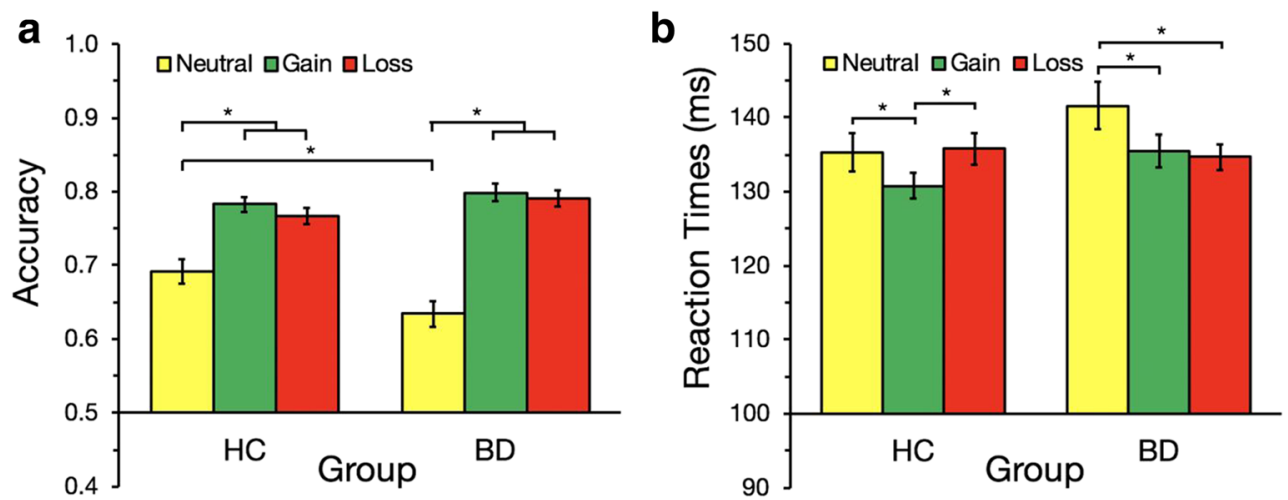

Fig. 3 Group-by-trial type interactions predicting (A) accuracy and (B) reactions times on the MID task. Error bars are 95\% confidence intervals with Cousineau-Morey corrections to reflect within-subject differences (Morey, 2008). Asterisks indicate significant differences $(p<.05)$

In other words, during reward striving, adolescent girls with $\mathrm{BD}$ appeared to engage cognitive control neural processes, as indexed by frontal theta, to a greater extent than healthy adolescent girls; interestingly, this effect was driven by healthy adolescent girls, who showed lower frontal theta than all other groups.

As seen in Fig. 5, the three-way interaction between group, trial type, and age revealed that in the $\mathrm{HC}$ group, there was a greater decrease in frontal theta with older age for loss trials than for gain trials $(\beta=.03, S E=.01, t(182)=2.22, p=.03)$ during the target anticipation phase. In the BD group, there were no such differences in frontal theta associations with age across trial types. In other words, among healthy adolescents, there was a greater decrease in cognitive control engagement with older age when responding to goal-striving cues with negative motivational value compared to cues with positive motivational value; this age association was not observed in adolescents with BD.

Feedback phase: Similar to target anticipation, during the feedback phase, there were significant main effects of group (BD $>\mathrm{HC}, \beta=.24, S E=.11, t(88)=2.14, p=.04$ ), sex (boys $>$ girls, $\beta=.31, S E=.09, t(88)=3.22, p<.01)$, and trial type on frontal theta (loss $>$ gain, $\beta=.04, S E=.01, t(169)=3.53, p<.001$; loss $>$ neutral, $\beta=.04, S E=.01, t(169)=3.55, p<.001)$ that were subsumed by a two-way group-by-sex interaction

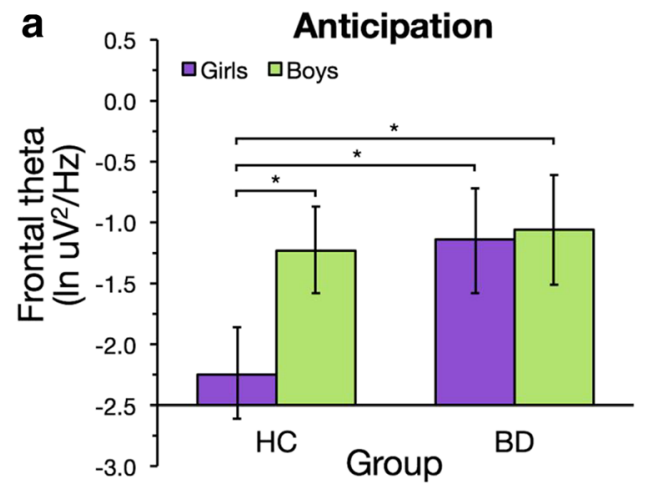

$(F(1,88)=7.77, p<.01$; Fig. 4B). As seen in the anticipation phase, this interaction indicated that frontal theta was lower in adolescent girls in the $\mathrm{HC}$ group compared to all other groups, including adolescent boys in the $\mathrm{HC}$ group $(\beta=.57$, $S E=.12, t(88)=4.62, p<.0001)$, adolescent girls in the BD group $(\beta=.50, S E=.14, t(88)=3.45, p<.001)$, and adolescent boys in the BD group $(\beta=.41, S E=.15, t(88)=2.79, p<.01)$ during the feedback phase. No other groups differed on frontal theta during feedback. This pattern suggests that even during reward attainment, healthy adolescent girls engage cognitive control neural processes to a lesser extent than adolescent girls with $\mathrm{BD}$ as well as adolescent boys with or without $\mathrm{BD}$.

\section{Frontal alpha asymmetry}

Anticipation phase: For frontal alpha asymmetry, a main effect of sex during the target anticipation phase (boys $>$ girls, $\beta=.29$, $S E=.11, t(88)=2.71, p<.01)$ was qualified by a two-way interaction between sex and trial type $(F(2,182)=3.23, p=.04)$. As seen in Figs. 6A and 6B, the difference in frontal alpha asymmetry between adolescent boys and girls (due to less relative left frontal alpha, indicating more relative left frontal activity, in boys) was greater during gain trials than during neutral trials $(\beta=.04, S E=.02, t(182)=2.49, p=.01)$. Thus, in both BD and $\mathrm{HC}$ groups, adolescent boys showed EEG activity suggesting

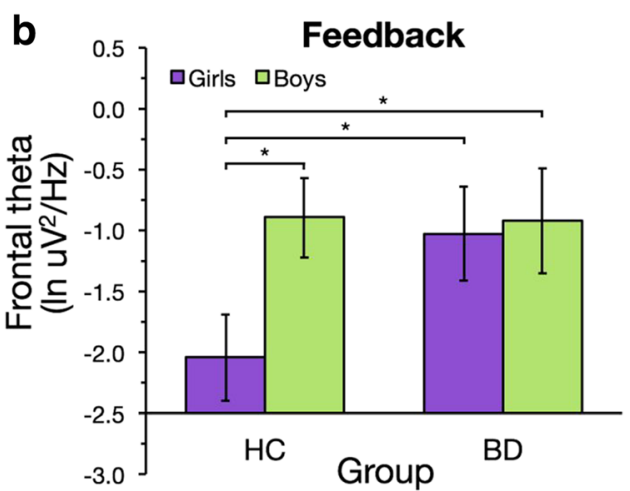

Fig. 4 Group-by-sex interactions predicting frontal theta during (A) target anticipation and (B) feedback phases of the monetary incentive delay (MID) task. Error bars are $95 \%$ confidence intervals. Asterisks indicate significant differences $(p<.05)$. $H C$ healthy control, $B D$ bipolar disorder 

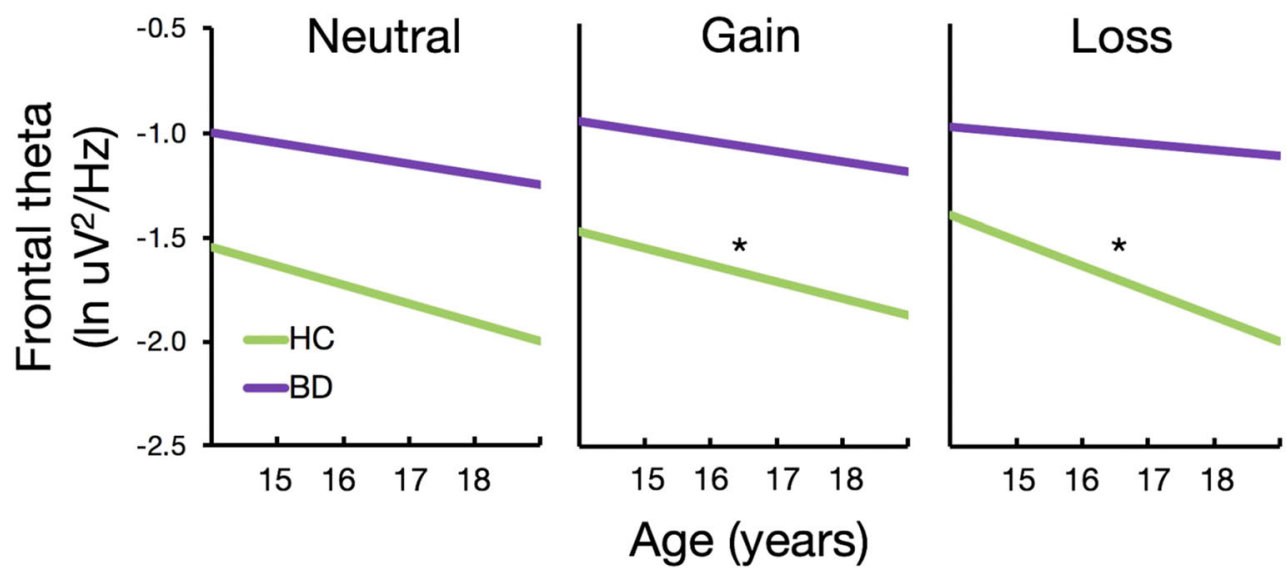

Fig. 5 Group-by-trial type-by-age interaction predicting frontal theta during target anticipation of the monetary incentive delay (MID) task. Asterisks indicate a significant difference between slopes $(p<.05)$, i.e.,

older age corresponded with a greater decrease in frontal theta during loss compared to gain trials only in the healthy control (HC) group. $B D$ bipolar disorder

more approach motivation to reward cues, or potentially less behavioral inhibition, than adolescent girls during the anticipation phase.

Feedback phase: As depicted in Figs. 6C and 6D, during the feedback phase, adolescent boys exhibited more relative left frontal activity than adolescent girls $(\beta=.29, S E=.11$, $t(88)=2.72, p<.01)$. There were no other significant effects on frontal alpha asymmetry during the feedback phase.

\section{Discussion}

This study examined neurophysiological differences between adolescents with BD and their healthy peers as they attempted to successfully gain or avoid losing monetary incentives, focusing on two factors implicated in BDs: cognitive control, as indexed by frontal theta, and approach motivation, as indexed by frontal alpha asymmetry. Contrary to our hypotheses, the
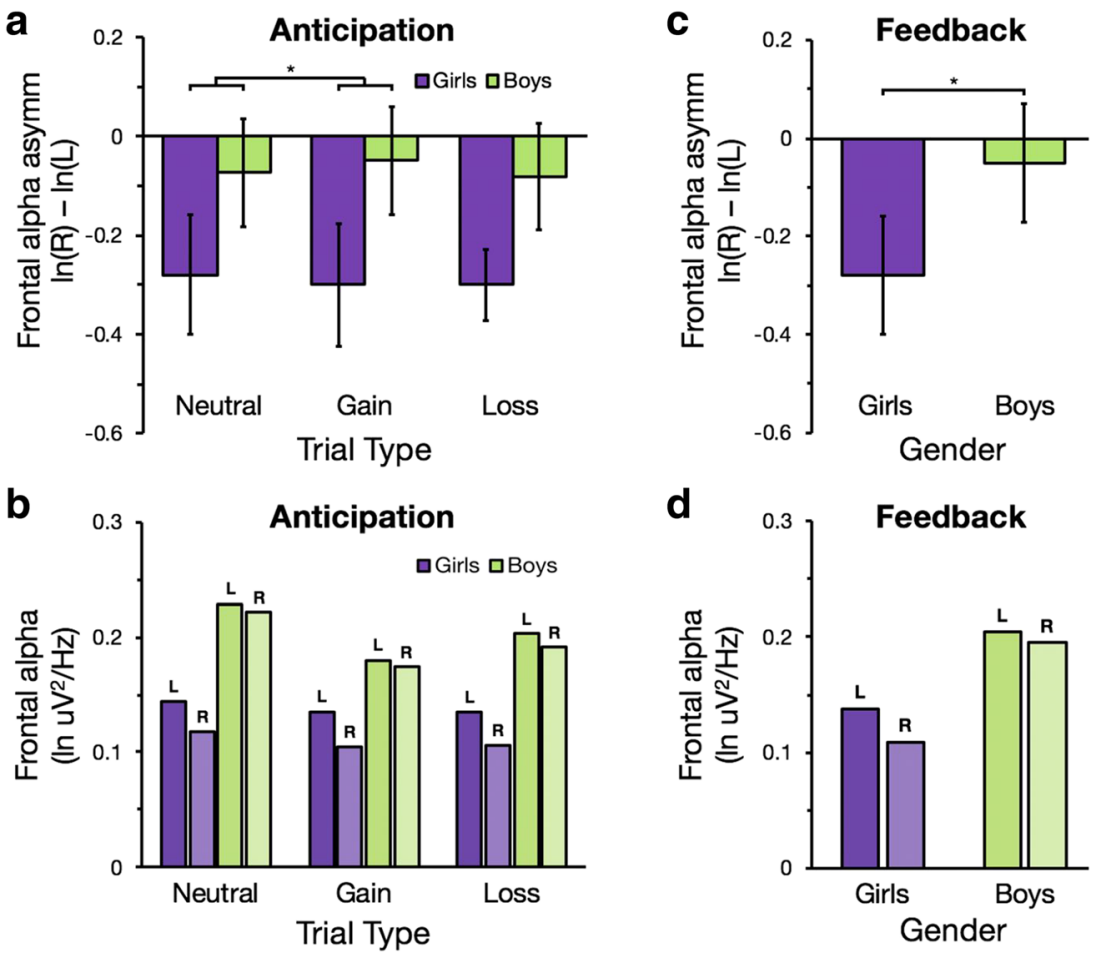

Fig. 6 Results for frontal alpha asymmetry during (A) target anticipation and $(\mathrm{C})$ feedback of the monetary incentive delay (MID) task. Panel A depicts a two-way interaction effect indicating a greater difference in frontal asymmetry between adolescent boys and girls in gain compared to neutral trials during the anticipation phase; panel $\mathrm{C}$ depicts greater relative left frontal activity (i.e., less negative frontal alpha asymmetry score) for adolescent boys than adolescent girls during the feedback phase. Frontal alpha in the left and right hemispheres during anticipation and feedback is additionally depicted in panels B and D. Error bars are 95\% confidence intervals Asterisks indicate significant differences $(p<.05) . L$ left hemisphere, $R$ right hemisphere 
pattern of findings supported increased engagement of cognitive control neural systems during reward striving and attainment in adolescent girls with BD compared to healthy adolescent girls. Importantly, this group difference was driven by adolescent girls without psychopathology, who displayed lower frontal theta compared to both adolescent girls with $\mathrm{BD}$ and adolescent boys with or without $\mathrm{BD}$, suggesting reduced recruitment of cognitive control neural networks in healthy adolescent girls during reward processing. Interestingly, no differences in frontal alpha asymmetry were found between adolescents with $\mathrm{BD}$ and adolescents without psychopathology, suggesting comparable engagement of approach motivation across groups during reward processing.

Previous research has identified differences based on sex in normative developmental changes in frontal theta EEG activity; however, the findings are mixed and may depend on the particular developmental stage and experimental context (e.g., Chorlian et al., 2015; Cragg et al., 2011; Kamarajan et al., 2008). Our primary finding was that healthy adolescent girls had less frontal theta than all other groups, including adolescents with BD and healthy adolescent boys. Yet, despite this neural activity difference, there were no differences in performance for either RTs or accuracy based on sex or group by sex interactions. In other words, healthy adolescent girls performed on par with healthy adolescent boys on the MID task despite engaging cognitive control neural systems to a lesser extent. Additional studies of adolescent development with larger samples and wider age ranges are necessary to fully examine sex differences in frontal theta engagement during reward processing and replicate the finding of lower frontal theta with comparable behavioral performance in healthy adolescent girls.

Another way to frame the findings is to consider sex differences within groups. Given the presence of sex differences in the control group and an absence of such differences in frontal theta in the BD group, it is possible that BD disrupts a normative sex difference in engagement of cognitive control during this particular age range (13-19 years old). However, it is unclear what component(s) of cognitive control frontal theta represented in this study; it is also possible that frontal theta taps into slightly different cognitive mechanisms in different groups, such as attention or arousal, or a different subcomponent of cognitive control. A large body of evidence has linked higher frontal theta with improved cognitive control (for metaanalyses, see Cavanagh \& Shackman, 2015), but "cognitive control" is a broad psychological concept encompassing multiple component processes that can be elicited for diverse reasons, such as response inhibition, cognitive flexibility, and conflict monitoring (Miller \& Cohen, 2001). Moreover, frontal theta can be affected by subjective fatigue (Wascher et al., 2014), task difficulty (Onton, Delorme, \& Makeig, 2005), and anxiety (Cavanagh \& Shackman, 2015) - suggesting that cognitive control engagement may increase during conditions in which individuals feel a need for greater effort to meet increasing task demands and/or maintain performance levels. Consequently, in this study, adolescents with $\mathrm{BD}$, particularly girls, may require increased engagement of cognitive control systems during reward striving and attainment to perform comparably to healthy adolescents. However, this increased cognitive control in adolescent BD may be insufficient for conditions without motivational value, as adolescents with BD still performed less accurately compared to adolescents without psychopathology on neutral trials.

The present findings of comparable frontal alpha asymmetry - which was used as a marker of approach motivation, consistent with past research (e.g., Coan \& Allen, 2004; Kelley, Hortensius, Schutter, \& Harmon-Jones, 2017) - in adolescents with $\mathrm{BD}$ and their healthy peers contradicts prior studies of adult BD. Adults with BD have exhibited increased relative left frontal activity compared to healthy controls during reward anticipation (e.g., Harmon-Jones et al., 2008) and at rest (Hayden et al., 2008). In this study, however, frontal alpha asymmetry did not differ between healthy adolescents and those with BD during reward anticipation or feedback. One possible explanation is that the ongoing normative changes in approach motivation that occur during development, in particular heightened reward sensitivity in healthy adolescents (e.g., Casey et al., 2008), could be obscuring differences between adolescents with and without BD. Abnormalities core to $\mathrm{BD}$, such as heightened approach motivation during reward pursuit and overall BAS dysregulation, may not be evident until adulthood, when the neural networks underlying behavioral approach levels have matured. Consistent with this interpretation, prior studies of adolescent BD found no link between self-report BAS sensitivity and manic symptom severity (Biuckians, Miklowitz, \& Kim, 2007) and no increased reward network activity in response to rewards (Urošević et al., 2016). Another possibility is that during adolescence, frontal alpha asymmetry may be less related to approach motivation than it is in adulthood. In support of this, a recent study of 99 healthy adolescents found no association between self-reported BAS and alpha asymmetry at rest (Schneider et al., 2016). While the authors indicated associations between alpha asymmetry and personality are more likely to emerge during emotion-eliciting tasks than at rest, in line with a capability model (Coan, Allen, \& McKnight, 2006), we also found no association between BAS and alpha asymmetry in this study, in which adolescents participated in a performancebased monetary reward task (see Supplemental Materials). Further, while considerable evidence links higher frontal alpha asymmetry in adults with greater approach motivation (for reviews, see Coan \& Allen, 2004; Kelley, Hortensius, Schutter, \& Harmon-Jones, 2017), there may be alternative interpretations of these findings. For example, frontal alpha asymmetry has also been linked to processes such as worry (Smith et al., 2016) and executive function (Ambrosini \& 
Vallesi, 2016), amongst others. Further longitudinal research is needed to clarify behavioral and personality correlates of frontal alpha asymmetry throughout development, as well as examine changes in frontal alpha asymmetry as adolescents with BD mature into adults.

Although group differences in frontal alpha asymmetry were not found, sex differences in frontal alpha asymmetry were observed. During both reward anticipation and feedback, adolescent boys exhibited greater relative left frontal activity than adolescent girls, consistent with sex differences in resting frontal alpha asymmetry in adults (e.g., Jaworska, Blier, Fusee, \& Knott, 2012; Santesso et al., 2008). In the present study, the difference in frontal alpha asymmetry between adolescent boys and girls was particularly pronounced during anticipation of monetary gain, suggesting positive motivational cues may be especially salient to adolescent boys. Along these lines, a substantial body of evidence has shown that adolescent boys and adult men report higher BAS/reward sensitivity and sensation-seeking behavior than their female counterparts (Steinberg et al., 2008; Urošević, Collins, Muetzel, Lim, \& Luciana, 2014).

The age range of adolescence in this study (from 13 to 19 years old) had limited effects on frontal theta or alpha asymmetry. Age was found to only interact with group and trial type to predict frontal theta during anticipation of reward. Specifically, with older age, healthy adolescents appeared to engage less cognitive control during trials with negative motivational value compared to trials with positive motivational value. This difference was not observed in adolescents with $\mathrm{BD}$, suggesting that as adolescents with $\mathrm{BD}$ mature, they may show less differentiation in cognitive control engagement based on valence of motivational cues. Past cross-sectional studies of healthy populations that have observed age-related differences in neural and behavioral indices of reward processes and cognitive control have included broader age ranges (Ernst et al., 2005; Galvan et al., 2006; Urošević et al., 2012). It is likely that broader age ranges spanning from prepuberty into early adulthood are needed to capture maturational changes in these neurophysiological indices of cognitive control and approach motivation.

\section{Limitations}

Despite multiple strengths of the present study (e.g., relatively large sample, well-established EEG indices of approach motivation and cognitive control, and a well-established reward paradigm), there are several limitations that need to be considered. First, as mentioned above, the limited age range and cross-sectional nature of this study prevent full exploration of developmental changes in cognitive control and approach motivation from adolescence into adulthood. Future longitudinal studies of cognitive control and behavioral approach in adolescents with and without $\mathrm{BD}$ across a broader age range are needed. Second, the majority ( $88 \%$ ) of adolescents with BD were taking medications at the time of the study, which may confound differences between healthy adolescents and those with BD. However, reviews of studies that examined effects of medication on neuroimaging findings in adult BD found that medications appeared to confer either no significant effects or "normalizing" effects on abnormal brain functioning in BD (Hafeman, Chang, Garrett, Sanders, \& Phillips, 2012; Phillips, Travis, Fagiolini, \& Kupfer, 2008). This suggests that including medicated individuals with BD may, if anything, obscure differences between healthy individuals and those with BD. Third, the adolescents with BD in this study spanned several different DSM-IV bipolar diagnoses and displayed variability in current mood state and co-morbid disorders. This sample of adolescents with BD $(n=43)$ is not large enough to analyze differences in these subcategories. However, this heterogeneity is also a strength, as this sample is much more clinically representative of BDs in the population. Moreover, repeated analyses while excluding adolescents with BDs and co-morbid ADHD, as well as analyses with and without current bipolar symptoms and IQ as covariates, yielded largely similar patterns of results (see Supplemental Materials), increasing confidence that the present findings are not driven by current state or co-morbid ADHD. Fourth, the MID task is not particularly cognitively demanding; thus, it may not be an ideal task for examining changes in cognitive control mechanisms via frontal theta. Indeed, studies have shown that task difficulty and complexity can yield differences in expression of frontal theta (Gevins, Smith, McEvoy, \& Yu, 1997; Onton et al., 2005). Yet the design of the MID task is ideal to examine changes in neural indices of BAS and cognitive control in two distinct phases of reward processing: striving and attainment, allowing for a more fine-grained analysis of when dysfunctional reward processing might occur in adolescent BD. Future studies might include assessments of EEG timefrequency in the context of more than one reward paradigm and at rest to determine the specificity of these observed effects. Finally, while this study examined differences in neural processes between healthy adolescents and adolescents with BD, it lacked a comparison group of adolescents with other psychiatric disorders to determine whether dysregulation of these processes is specific to BD.

\section{Conclusions}

The present findings suggest that healthy adolescents, in particular adolescent girls, exhibit decreased engagement of cognitive control systems during reward pursuit compared to both healthy adolescent boys and adolescents with BD of either sex. This may indicate a normative sex difference in cognitive control that is disrupted in adolescent BD. This cognitive 
control abnormality is observed in context of comparable engagement of approach motivation among adolescents with $\mathrm{BD}$ compared with their healthy peers. In addition to furthering our understanding of adolescent $\mathrm{BD}$, these findings shed light on normative development of approach motivation and cognitive control neural systems by highlighting sex differences in adolescence of these networks' involvement during reward pursuit and consummation.

Acknowledgements This research was supported by NIMH Grant K01 MH093621 to Snežana Urošević, PhD and the University of Minnesota's Center for Neurobehavioral Development. Drs. Urošević's and Sponheim's efforts were also partially supported by the Minneapolis VA Health Care System. The contents do not represent the views of the U.S. Department of Veterans Affairs or the United States Government. The authors declare no conflicts of interest with respect to their authorship or the publication of this article. Finally, the authors would like to thank all the research staff that contributed to data collection and especially the research participants and their families for their participation in this study.

Open Practices Statement The experimental procedure reported in this article was not formally preregistered and neither the data nor the materials have been made available on a permanent third-party archive; however, requests for the data or materials can be sent via email to the corresponding author at snezana.urosevic@gmail.com.

\section{References}

Alloy, L. B., Abramson, L. Y., Walshaw, P. D., Cogswell, A., Grandin, L. D., Hughes, M. E., ... Hogan, M. E. (2008). Behavioral Approach System and Behavioral Inhibition System sensitivities and bipolar spectrum disorders: Prospective prediction of bipolar mood episodes. Bipolar Disorders, 10(2), 310-322. https://doi.org/10.1111/ j.1399-5618.2007.00547.x

Alloy, L. B., Urošević, S., Abramson, L. Y., Jager-Hyman, S., Nusslock, R., Whitehouse, W. G., \& Hogan, M. (2012). Progression along the bipolar spectrum: A longitudinal study of predictors of conversion from bipolar spectrum conditions to bipolar I and II disorders. Journal of Abnormal Psychology, 121(1), 16-27. https://doi.org/ 10.1037/a0023973

Ambrosini, E., \& Vallesi, A. (2016). Asymmetry in prefrontal restingstate EEG spectral power underlies individual differences in phasic and sustained cognitive control. NeuroImage. https://doi.org/10. 1016/j.neuroimage.2015.09.035

Atagun, M., Guntekin, B., Ozerdem, A., Tulay, E., \& Basar, E. (2013). Decrease of theta response in euthymic bipolar patients during an oddball paradigm. Cogn Neurodyn. https://doi.org/10.1007/s11571012-9228-7

Axelson, D., Birmaher, B., Strober, M., Gill, M. K., Valeri, S., Chiappetta, L., ... Keller, M. (2006). Phenomenology of children and adolescents with bipolar spectrum disorders. Archives of General Psychiatry, 63(10), 1139-1148. https://doi.org/10.1001/archpsyc. 63.10.1139

Axelson, D., Birmaher, B., Zelazny, J., Kaufman, J., \& Gill, M. K. (2009). The Schedule for Affective Disorders and Schizophrenia-Present and Lifetime Version (K-SADS-PL) 2009 Working Draft. Advanced Centre for Intervention and Services Research, Western Psychiatric Institute and Clinics.

Baayen, R. H., Davidson, D. J., \& Bates, D. M. (2008). Mixed-effects modeling with crossed random effects for subjects and items.
Journal of Memory and Language, 59(4), 390-412. https://doi. org/10.1016/j.jml.2007.12.005

Baldessarini, R. J., Pompili, M., \& Tondo, L. (2006). Suicide in bipolar disorder: Risks and management. CNS Spectrums. https://doi.org/ $10.1017 / \mathrm{S} 1092852900014681$

Bates, D., Mächler, M., Bolker, B., \& Walker, S. (2015). Fitting Linear Mixed-Effects Models Using lme4. Journal of Statistical Software, 67(1), 1-48. https://doi.org/10.18637/jss.v067.i01

Bauer, M. S., Crits Christoph, P., Ball, W. A., Dewees, E., Mcallister, T., Alahi, P., ... Whybrow, P. C. (1991). Independent Assessment of Manic and Depressive Symptoms by Self-rating: Scale Characteristics and Implications for the Study of Mania. Archives of General Psychiatry, 48(9), 807-812. https://doi.org/10.1001/ archpsyc.1991.01810330031005

Beesdo, K., Höfler, M., Leibenluft, E., Lieb, R., Bauer, M., \& Pfennig, A. (2009). Mood episodes and mood disorders: Patterns of incidence and conversion in the first three decades of life. Bipolar Disorders, 11(6), 637-649. https://doi.org/10.1111/j.1399-5618.2009.00738.x

Bermpohl, F., Kahnt, T., Dalanay, U., Hägele, C., Sajonz, B., Wegner, T., ... Heinz, A. (2010). Altered representation of expected value in the orbitofrontal cortex in Mania. Human Brain Mapping, 31(7), 958969. https://doi.org/10.1002/hbm.20909

Birmaher, B., Gill, M. K., Axelson, D. A., Goldstein, B. I., Goldstein, T. R., Yu, H., ... Keller, M. B. (2014). Longitudinal trajectories and associated baseline predictors in youths with bipolar spectrum disorders. American Journal of Psychiatry, 171(9), 990-999. https:// doi.org/10.1176/appi.ajp.2014.13121577

Biuckians, A., Miklowitz, D. J., \& Kim, E. Y. (2007). Behavioral activation, inhibition and mood symptoms in early-onset bipolar disorder. Journal of Affective Disorders, 97(1-3), 71-76. https://doi.org/10. 1016/j.jad.2006.07.005

Burgess, A P., \& Gruzelier, J. H. (1997). Short duration synchronization of human theta rhythm during recognition memory. Neuroreport, 8(4), 1039-1042. https://doi.org/10.1097/00001756-19970303000044

Casey, B. J., Jones, R. M., \& Hare, T. A. (2008). The adolescent brain. Annals of the New York Academy of Sciences. https://doi.org/10. 1196/annals.1440.010

Cavanagh, J. F., \& Shackman, A. J. (2015). Frontal midline theta reflects anxiety and cognitive control: meta-analytic evidence. Journal of Physiology, Paris, 109(1-3), 3-15. https://doi.org/10.1016/j. jphysparis.2014.04.003

Chorlian, D. B., Rangaswamy, M., Manz, N., Kamarajan, C., Pandey, A. K., Edenberg, H., ... Porjesz, B. (2015). Gender modulates the development of theta event related oscillations in adolescents and young adults. Behavioural Brain Research. https://doi.org/10. 1016/j.bbr.2015.06.020

Coan, J. A., \& Allen, J. J. (2004). Frontal EEG asymmetry as a moderator and mediator of emotion. Biological Psychology. https://doi.org/10. 1016/j.biopsycho.2004.03.002

Coan, J. A., Allen, J. J. B., \& McKnight, P. E. (2006). A capability model of individual differences in frontal EEG asymmetry. Biological Psychology, 72(2), 198-207. https://doi.org/10.1016/j.biopsycho. 2005.10.003

Cragg, L., Kovacevic, N., Mcintosh, A. R., Poulsen, C., Martinu, K., Leonard, G., \& Paus, T. (2011). Maturation of EEG power spectra in early adolescence: A longitudinal study. Developmental Science. https://doi.org/10.1111/j.1467-7687.2010.01031.x

Delorme, A., \& Makeig, S. (2004). EEGLAB: An open source toolbox for analysis of single-trial EEG dynamics including independent component analysis. Journal of Neuroscience Methods, 134(1), 921. https://doi.org/10.1016/j.jneumeth.2003.10.009

Depue, R. A., \& Iacono, W. G. (1989). Neurobehavioral Aspects of Affective Disorders. Annual Review of Psychology, 40(1), 457492. https://doi.org/10.1146/annurev.ps.40.020189.002325 
Dutra, S. J., Cunningham, W. A., Kober, H., \& Gruber, J. (2015). Elevated striatal reactivity across monetary and social rewards in bipolar I disorder. Journal of Abnormal Psychology, 124(4), 890904. https://doi.org/10.1037/abn0000092

Ernst, M., Nelson, E. E., Jazbec, S., McClure, E. B., Monk, C. S., Leibenluft, E., ... Pine, D. S. (2005). Amygdala and nucleus accumbens in responses to receipt and omission of gains in adults and adolescents. NeuroImage, 25(4), 1279-1291. https://doi.org/10. 1016/j.neuroimage.2004.12.038

Fulford, D., Johnson, S. L., Llabre, M. M., \& Carver, C. S. (2010). Pushing and coasting in dynamic goal pursuit: Coasting is attenuated in bipolar disorder. Psychological Science, 21(7), 1021-1027. https://doi.org/10.1177/0956797610373372

Galvan, A., Hare, T. A., Parra, C. E., Penn, J., Voss, H., Glover, G., \& Casey, B. J. (2006). Earlier Development of the Accumbens Relative to Orbitofrontal Cortex Might Underlie Risk-Taking Behavior in Adolescents. Journal of Neuroscience, 26(25), 68856892. https://doi.org/10.1523/JNEUROSCI.1062-06.2006

Gevins, A., Smith, M. E., McEvoy, L., \& Yu, D. (1997). High-resolution EEG mapping of cortical activation related to working memory: Effects of task difficulty, type of processing, and practice. Cerebral Cortex, 7(4), 374-385. https://doi.org/10.1093/cercor/7.4. 374

Goldstein, B. I., Birmaher, B., Carlson, G. A., DelBello, M. P., Findling, R. L., Fristad, M., .. Youngstrom, E. A. (2017). The International Society for Bipolar Disorders Task Force report on pediatric bipolar disorder: Knowledge to date and directions for future research. Bipolar Disorders. https://doi.org/10.1111/bdi.12556

Greischar, L. L., Burghy, C. A., Van Reekum, C. M., Jackson, D. C., Pizzagalli, D. A., Mueller, C., \& Davidson, R. J. (2004). Effects of electrode density and electrolyte spreading in dense array electroencephalographic recording. Clinical Neurophysiology. https://doi.org/ 10.1016/j.clinph.2003.10.028

Hafeman, D. M., Axelson, D., Demeter, C., Findling, R. L., Fristad, M. A., Kowatch, R. A., ... Birmaher, B. (2013). Phenomenology of bipolar disorder not otherwise specified in youth: A comparison of clinical characteristics across the spectrum of manic symptoms. Bipolar Disorders, 15(3), 240-252. https://doi.org/10.1111/bdi. 12054

Hafeman, D. M., Chang, K. D., Garrett, A. S., Sanders, E. M., \& Phillips, M. L. (2012). Effects of medication on neuroimaging findings in bipolar disorder: An updated review. Bipolar Disorders. https:// doi.org/10.1111/j.1399-5618.2012.01023.x

Harmon-Jones, E., Abramson, L. Y., Nusslock, R., Sigelman, J. D., Urošević, S., Turonie, L. D., ... Fearn, M. (2008). Effect of Bipolar Disorder on Left Frontal Cortical Responses to Goals Differing in Valence and Task Difficulty. Biological Psychiatry, 63(7), 693-698. https://doi.org/10.1016/j.biopsych.2007.08.004

Harmon-Jones, E., Abramson, L. Y., Sigelman, J., Bohlig, A., Hogan, M. E., \& Harmon-Jones, C. (2002). Proneness to hypomania/mania symptoms or depression Symptoms and asymmetrical frontal cortical responses to an anger-evoking event. Journal of Personality and Social Psychology, 82(4), 610-618. https://doi.org/10.1037//00223514.82.4.610

Harmon-Jones, E., Gable, P. A., \& Peterson, C. K. (2010). The role of asymmetric frontal cortical activity in emotion-related phenomena: A review and update. Biological Psychology. https://doi.org/10. 1016/j.biopsycho.2009.08.010

Hayden, E. P., Bodkins, M., Brenner, C., Shekhar, A., Nurnberger, J. I., O'Donnell, B. F., \& Hetrick, W. P. (2008). A Multimethod Investigation of the Behavioral Activation System in Bipolar Disorder. Journal of Abnormal Psychology, 117(1), 164-170. https://doi.org/10.1037/0021-843X.117.1.164

Hidiroğlu, C., Demirci Esen, Ö., Tunca, Z., Neslihan Gårz Yalçìn, Ș., Lombardo, L., Glahn, D. C., \& Özerdem, A. (2013). Can risktaking be an endophenotype for bipolar disorder? A study on patients with bipolar disorder type I and their first-degree relatives. Journal of the International Neuropsychological Society. https://doi. org/10.1017/S1355617713000015

Jaworska, N., Blier, P., Fusee, W., \& Knott, V. (2012). Alpha power, alpha asymmetry and anterior cingulate cortex activity in depressed males and females. Journal of Psychiatric Research, 46(11), 1483-1491. https://doi.org/10.1016/j.jpsychires.2012.08.003

Johnson, S. L., Fulford, D., \& Carver, C. S. (2012). The Double-Edged Sword of Goal Engagement: Consequences of Goal Pursuit in Bipolar Disorder. Clinical Psychology and Psychotherapy, 19(4), 352-362. https://doi.org/10.1002/cpp.1801

Judd, L. L., Akiskal, H. S., Schettler, P. J., Coryell, W., Endicott, J., Maser, J. D., ... Keller, M. B. (2003). A prospective investigation of the natural history of the long-term weekly symptomatic status of bipolar II disorder. Archives of General Psychiatry, 60(3), 261-269. https://doi.org/10.1001/archpsyc.60.3.261

Kamarajan, C., Rangaswamy, M., Chorlian, D. B., Manz, N., Tang, Y., Pandey, A. K., ... Porjesz, B. (2008). Theta oscillations during the processing of monetary loss and gain: A perspective on gender and impulsivity. Brain Research. https://doi.org/10.1016/j.brainres. 2008.06.051

Kang, S. S., MacDonald III, A. W., Chafee, M. V, Im, C.-H., Bernat, E. M., Davenport, N. D., \& Sponheim, S. R. (2018). Abnormal cortical neural synchrony during working memory in schizophrenia. Clinical Neurophysiology, 129(1), 210-221. https://doi.org/10. 1016/j.clinph.2017.10.024

Kelley, N. J., Hortensius, R., Schutter, D. J. L. G., \& Harmon-Jones, E. (2017). The relationship of approach/avoidance motivation and asymmetric frontal cortical activity: A review of studies manipulating frontal asymmetry. International Journal of Psychophysiology. https://doi.org/10.1016/j.ijpsycho.2017.03.001

Knutson, B., Fong, G. W., Adams, C. M., Varner, J. L., \& Hommer, D. (2001). Dissociation of reward anticipation and outcome with eventrelated fMRI. NeuroReport, 12(17), 3683-3687. https://doi.org/10. 1097/00001756-200112040-00016

Knutson, B., Westdorp, A., Kaiser, E., \& Hommer, D. (2000). FMRI visualization of brain activity during a monetary incentive delay task. NeuroImage, 12(1), 20-27. https://doi.org/10.1006/nimg. 2000.0593

Kuznetsova, A., Brockhoff, P. B., \& Christensen, R. H. B. (2014). lmerTest: Tests for random and fixed effects for linear mixed effect models (lmer objects of lme4 package). R Package Version. http:// CRAN.R-project.org/package=lmerTest

Ladouceur, C. D., Farchione, T., Diwadkar, V., Pruitt, P., Radwan, J., Axelson, D. A., ... Phillips, M. L. (2011). Differential patterns of abnormal activity and connectivity in the amygdalaprefrontal circuitry in bipolar-I and bipolar-NOS youth. Journal of the American Academy of Child and Adolescent Psychiatry, 50(12). https://doi.org/10.1016/j.jaac.2011.09.023

Lazarev, V. V. (1998). On the intercorrelation of some frequency and amplitude parameters of the human EEG and its functional significance. Communication II: Neurodynamic imbalance in endogenous asthenic-like disorders. International Journal of Psychophysiology, 29(3), 277-289. https://doi.org/10.1016/S0167-8760(98)00008-7

Liu, X., Hairston, J., Schrier, M., \& Fan, J. (2011). Common and distinct networks underlying reward valence and processing stages: A metaanalysis of functional neuroimaging studies. Neuroscience and Biobehavioral Reviews. https://doi.org/10.1016/j.neubiorev.2010. 12.012

Luna, B., Padmanabhan, A., \& O'Hearn, K. (2010). What has fMRI told us about the Development of Cognitive Control through Adolescence? Brain and Cognition. https://doi.org/10.1016/j. bandc.2009.08.005

Merikangas, K. R., Jin, R., He, J.-P., Kessler, R. C., Lee, S., Sampson, N. A., ... Zarkov, Z. (2011). Prevalence and Correlates of Bipolar Spectrum Disorder in the World Mental Health Survey Initiative. 
Archives of General Psychiatry, 68(3), 241. https://doi.org/10.1001/ archgenpsychiatry.2011.12

Meyer, B., Johnson, S. L., \& Carver, C. S. (1999). Exploring Behavioral Activation and Inhibition Sensitivities Among College Students at Risk for Bipolar Spectrum Symptomatology. Journal of Pychopathology and Behavioral Assessment, 21(4), 275-292. https://doi.org/10.1023/A:1022119414440

Meyer, B., Johnson, S. L., \& Winters, R. (2001). Responsiveness to threat and incentive in bipolar disorder: Relations of the BIS/BAS scales with symptoms. Journal of Psychopathology Behavioral Assessment, 23(3), 133-143. https://doi.org/10.1023/A: 1010929402770

Michelini, G., Kitsune, V., Vainieri, I., Hosang, G. M., Brandeis, D., Asherson, P., \& Kuntsi, J. (2018). Shared and Disorder-Specific Event-Related Brain Oscillatory Markers of Attentional Dysfunction in ADHD and Bipolar Disorder. Brain Topography. https://doi.org/10.1007/s10548-018-0625-Z

Miller, E. K., \& Cohen, J. D. (2001). An integrative theory of prefrontal cortex function. Annual Review of Neuroscience, 24(1), 167-202. https://doi.org/10.1146/annurev.neuro.24.1.167

Missonnier, P., Deiber, M. P., Gold, G., Millet, P., Gex-Fabry Pun, M., Fazio-Costa, L., ... Ibáñez, V. (2006). Frontal theta event-related synchronization: Comparison of directed attention and working memory load effects. Journal of Neural Transmission. https://doi. org/10.1007/s00702-005-0443-9

Nich, C., \& Carroll, K. (1997). Now you see it, now you don't: a comparison of traditional versus random-effects regression models in the analysis of longitudinal follow-up data from a clinical trial. $J$ Consult Clin Psychol, 65(2), 252-261. Retrieved from http://www. ncbi.nlm.nih.gov/entrez/query.fcgi? cmd=Retrieve \&db= PubMed\&dopt $=$ Citation $\&$ list uids $=9086688$

Nusslock, R., Abramson, L. Y., Harmon-Jones, E., Alloy, L. B., \& Hogan, M. E. (2007). A goal-striving life event and the onset of hypomanic and depressive episodes and symptoms: Perspective from the behavioral approach system (BAS) dysregulation theory. Journal of Abnormal Psychology, 116(1), 105-115. https://doi.org/ 10.1037/0021-843X.116.1.105

Nusslock, R., Almeida, J. R. C., Forbes, E. E., Versace, A., Frank, E., Labarbara, E. J., ... Phillips, M. L. (2012). Waiting to win: Elevated striatal and orbitofrontal cortical activity during reward anticipation in euthymic bipolar disorder adults. Bipolar Disorders, 14(3), 249 260. https://doi.org/10.1111/j.1399-5618.2012.01012.x

Olson, E. A., Hooper, C. J., Collins, P., \& Luciana, M. (2007). Adolescents' performance on delay and probability discounting tasks: Contributions of age, intelligence, executive functioning, and self-reported externalizing behavior. Personality and Individual Differences, 43(7), 1886-1897. https://doi.org/10.1016/ j.paid.2007.06.016

Onton, J., Delorme, A., \& Makeig, S. (2005). Frontal midline EEG dynamics during working memory. NeuroImage, 27(2), 341-356. https://doi.org/10.1016/j.neuroimage.2005.04.014

Pavuluri, M. N., Passarotti, A. M., Harral, E. M., \& Sweeney, J. A. (2009). An fMRI study of the neural correlates of incidental versus directed emotion processing in pediatric bipolar disorder. Journal of the American Academy of Child and Adolescent Psychiatry, 48(3), 308-319. https://doi.org/10.1097/CHI.0b013e3181948fc7

Perlis, R. H., Dennehy, E. B., Miklowitz, D. J., Delbello, M. P., Ostacher, M., Calabrese, J. R., ... Sachs, G. (2009). Retrospective age at onset of bipolar disorder and outcome during two-year follow-up: Results from the STEP-BD study. Bipolar Disorders, 11(4), 391-400. https://doi.org/10.1111/j.1399-5618.2009.00686.x

Perlis, R. H., Miyahara, S., Marangell, L. B., Wisniewski, S. R., Ostacher, M., DelBello, M. P., ... Nierenberg, A. A. (2004). Long-term implications of early onset in bipolar disorder: Data from the first 1000 participants in the Systematic Treatment Enhancement Program for
Bipolar Disorder (STEP-BD). Biological Psychiatry, 55(9), 875881. https://doi.org/10.1016/j.biopsych.2004.01.022

Phillips, M. L., Travis, M. J., Fagiolini, A., \& Kupfer, D. J. (2008). Medication effects in neuroimaging studies of bipolar disorder. American Journal of Psychiatry. https://doi.org/10.1176/appi.ajp. 2007.07071066

Pompili, M., Gonda, X., Serafini, G., Innamorati, M., Sher, L., Amore, M., ... Girardi, P. (2013). Epidemiology of suicide in bipolar disorders: a systematic review of the literature. Bipolar Disorders. https:// doi.org/10.1111/bdi.12087

Porter, J. N., Roy, A. K., Benson, B., Carlisi, C., Collins, P. F., Leibenluft, E., ... Ernst, M. (2015). Age-related changes in the intrinsic functional connectivity of the human ventral vs. dorsal striatum from childhood to middle age. Developmental Cognitive Neuroscience, 11, 83-95. https://doi.org/10.1016/j.den.2014.08.011

Quaedflieg, C. W. E. M., Meyer, T., Smulders, F. T. Y., \& Smeets, T. (2015). The functional role of individual-alpha based frontal asymmetry in stress responding. Biological Psychology, 104, 75-81. https://doi.org/10.1016/j.biopsycho.2014.11.014

R Core Team. (2013). R Core Team. R: A language and environment for statistical computing. R Foundation for Statistical Computing, Vienna, Austria., ISBN 3-900051-07-0, URL http://www.Rproject.org/. Retrieved from http://www.mendeley.com/research/rlanguage-environment-statistical-computing-96/\%5Cnpapers2:// publication/uuid/A 1207 D A B - 22D3-4A 04-82 F B D4DD5AD57C28

Rommel, A. S., Kitsune, G. L., Michelini, G., Hosang, G. M., Asherson, P., McLoughlin, G., ... Kuntsi, J. (2016). Commonalities in EEG Spectral Power Abnormalities Between Women With ADHD and Women With Bipolar Disorder During Rest and Cognitive Performance. Brain Topography, 29(6), 856-866. https://doi.org/ 10.1007/s10548-016-0508-0

Santesso, D. L., Segalowitz, S. J., Ashbaugh, A. R., Antony, M. M., McCabe, R. E., \& Schmidt, L. A. (2008). Frontal EEG asymmetry and sensation seeking in young adults. Biological Psychology, 78(2), 164-172. https://doi.org/10.1016/j.biopsycho.2008.02.003

Schneider, M., Chau, L., Mohamadpour, M., Stephens, N., Arya, K., \& Grant, A. (2016). EEG asymmetry and BIS/BAS among healthy adolescents. Biological Psychology, 120, 142-148. https://doi.org/ 10.1016/j.biopsycho.2016.09.004

Schürhoff, F., Bellivier, F., Jouvent, R., Mouren-Siméoni, M.-C., Bouvard, M., Allilaire, J.-F., \& Leboyer, M. (2000). Early and late onset bipolar disorders: two different forms of manic-depressive illness? Journal of Affective Disorders, 58(3), 215-221. https://doi. org/10.1016/S0165-0327(99)00111-1

Singh, M. K., Chang, K. D., Kelley, R. G., Cui, X., Sherdell, L., Howe, M. E., ... Reiss, A. L. (2013). Reward processing in adolescents with bipolar I disorder. Journal of the American Academy of Child and Adolescent Psychiatry. https://doi.org/10.1016/j.jaac.2012.10. 004

Smith, E. E., Zambrano-Vazquez, L., \& Allen, J. J. B. (2016). Patterns of alpha asymmetry in those with elevated worry, trait anxiety, and obsessive-compulsive symptoms: A test of the worry and avoidance models of alpha asymmetry. Neuropsychologia. https://doi.org/10. 1016/j.neuropsychologia.2016.03.010

Somerville, L. H., Hare, T., \& Casey, B. J. (2011). Frontostriatal Maturation Predicts Cognitive Control Failure to Appetitive Cues in Adolescents. Journal of Cognitive Neuroscience, 23(9), 21232134. https://doi.org/10.1162/jocn.2010.21572

Steinberg, L., Albert, D., Cauffman, E., Banich, M., Graham, S., \& Woolard, J. (2008). Age Differences in Sensation Seeking and Impulsivity as Indexed by Behavior and Self-Report: Evidence for a Dual Systems Model. Developmental Psychology, 44(6), 1764 1778. https://doi.org/10.1037/a0012955 
Swann, A. C. (2010). Mechanisms of impulsivity in bipolar disorder and related illness. Epidemiologia e Psichiatria Sociale, 19(2), 120-130. https://doi.org/10.1705/496.5885

Tozzi, F., Manchia, M., Galwey, N. W., Severino, G., Del Zompo, M., Day, R., ... Muglia, P. (2011). Admixture analysis of age at onset in bipolar disorder. Psychiatry Research, 185(1-2), 27-32. https://doi. org/10.1016/j.psychres.2009.11.025

Urošević, S., Abramson, L. Y., Alloy, L. B., Nusslock, R., Harmon-Jones, E., Bender, R., \& Hogan, M. E. (2010). Increased rates of events that activate or deactivate the behavioral approach system, but not events related to goal attainment, in bipolar spectrum disorders. Journal of Abnormal Psychology, 119(3), 610-615. https://doi.org/10.1037/ a0019533

Urošević, S., Abramson, L. Y., Harmon-Jones, E., \& Alloy, L. B. (2008). Dysregulation of the behavioral approach system (BAS) in bipolar spectrum disorders: review of theory and evidence. Clinical Psychology Review, 28(7), 1188-205. https://doi.org/10.1016/j.cpr. 2008.04.004

Urošević, S., Collins, P., Muetzel, R., Lim, K., \& Luciana, M. (2012). Longitudinal changes in behavioral approach system sensitivity and brain structures involved in reward processing during adolescence. Developmental Psychology, 48(5), 1488-1500. https://doi.org/10. 1037/a0027502

Urošević, S., Collins, P., Muetzel, R., Lim, K. O., \& Luciana, M. (2014). Pubertal status associations with reward and threat sensitivities and subcortical brain volumes during adolescence. Brain and Cognition, 89, 15-26. https://doi.org/10.1016/j.bandc.2014.01.007

Urošević, S., Luciana, M., Jensen, J. B., Youngstrom, E. A., \& Thomas, K. M. (2016). Age associations with neural processing of reward anticipation in adolescents with bipolar disorders. NeuroImage: Clinical, 11, 476-485. https://doi.org/10.1016/j.nicl.2016.03.013

Velanova, K., Wheeler, M. E., \& Luna, B. (2008). Maturational changes in anterior cingulate and frontoparietal recruitment support the development of error processing and inhibitory control. Cerebral Cortex, 18(11), 2505-2522. https://doi.org/10.1093/cercor/bhn012

Wascher, E., Rasch, B., Sänger, J., Hoffmann, S., Schneider, D., Rinkenauer, G., ... Gutberlet, I. (2014). Frontal theta activity reflects distinct aspects of mental fatigue. Biological Psychology, 96, 57-65. https://doi.org/10.1016/j.biopsycho.2013.11.010

Wechsler, D. (2011). WASI-II: Wechsler abbreviated scale of intelligence-Second Edition (WASI-II). San Antonio, TX: NCS Pearson.

Wegbreit, E., Cushman, G. K., Puzia, M. E., Weissman, A. B., Kim, K. L., Laird, A. R., \& Dickstein, D. P. (2014). Developmental metaanalyses of the functional neural correlates of bipolar disorder. JAMA Psychiatry, 71(8), 926-935. https://doi.org/10.1001/ jamapsychiatry.2014.660

Whiteford, H. A., Degenhardt, L., Rehm, J., Baxter, A. J., Ferrari, A. J., Erskine, H. E., ... Vos, T. (2013). Global burden of disease attributable to mental and substance use disorders: Findings from the Global Burden of Disease Study 2010. The Lancet, 382(9904), 1575-1586. https://doi.org/10.1016/S0140-6736(13)61611-6

Youngstrom, E. A. (2009). Definitional issues in bipolar disorder across the life cycle. Clinical Psychology: Science and Practice. https://doi. org/10.1111/j.1468-2850.2009.01154.x

Publisher's note Springer Nature remains neutral with regard to jurisdictional claims in published maps and institutional affiliations. 